\title{
Production of Cellulase from Talaromyces emersonii and Evaluation of Its Application in Eco-Friendly Functional Finishing of Jute-Based Fabrics
}

\author{
Isidore Gomes ${ }^{1 *}$, Palash Kumar Sarkar², Sabita Rezwana Rahman², M Abdur Rahim¹ and Donald James Gomes² \\ ${ }^{1}$ Bangladesh Jute Research Institute (BJRI), Manik Mia Avenue, Sher-e-Bangla Nagar, Dhaka 1207, Bangladesh, ${ }^{2}$ Department of Microbiology, \\ University of Dhaka, Dhaka 1000, Bangladesh
}

[Received 10 July 2007; Accepted 08 December 2007]

\begin{abstract}
Use of cellulase for biofinishing and biostoning are standard eco-friendly techniques to achieve desirable appearance and softness for fabrics. Thermophilic fungus Talaromyces emersonii was able to produce high level of cellulase in shaken cultures using sugar cane bagasse as substrate. An optimisation of the medium composition in submerged fermentation was carried out using statistical experiment designs aiming at a low cost medium composition for enzyme production. Additionally, the influence of several cultural conditioned was investigated. Evaluation of the effectiveness of the enzyme on biofinishing and biostoning was studied by treating the jute-cotton union fabrics and Hessians with the enzyme preparation. The enzyme enhanced whiteness, brightness and softness of the treated materials. Pilling and fuzziness of the treated samples were remarkably reduced without loss of tensile strength beyond acceptable limits. The cellulase preparation was also applied in biostoning process at a laboratory scale. The enzyme exhibited good biowash effect on coloured jute-based fabrics. The treatment also increased gloss or lustre, improved fabric handle, and increased durable softness. However, the treated fabrics did not show much worn out look due to abrasion resistance of the fabrics.
\end{abstract}

Keywords: Talaromyces emersonii, Cellulase, Medium optimisation, Biofinishing, Biostoning

\section{Introduction}

Eco-friendly wet processings of textiles are major concerns of textile producers nowadays to attain high quality products without diversely affecting the environment quality and the enduser health ${ }^{1}$. Enzymatic processing of textile offers many advantages when compared to traditional chemical methods, namely, enzymes use significantly less water, less energy, and fewer chemicals than traditional methods ${ }^{2}$. In addition, wastewater from enzymatic treatments is readily biodegradable and does not pose an environmental threat ${ }^{1}$. Enzymatic treatments have been used for a long time to remove the starch size that's added to cotton yarns to smooth and protect them from breaks during weaving. New trends in eco-friendly textile finishing include biofinishing to remove fibre fuzz and pills from fabric surface, and biostoning to remove colour and softening denim fabrics for a stonewashed effect ${ }^{2-7}$. However, jute-based textile industry very limited practical experience to cope with these two new trends.

Newly manufactured Jute fabrics and Jute-cotton blend fabrics have a handle that is rather hard and stiff unless they are treated with finishing components ${ }^{8}$. Furthermore, the fabric surface is not always smooth due to small fuzzy fibres protruding from the individual jute fibres as a result fabrics made from jute and cotton (JC) blends have a distinct prickly sensation when in contact with the skin. This is due to rigid jute fibres protruding from the surface $^{9-10}$. Unless the quality of the fabric is improved, garments made with JC are not smooth and soft and will not perform well. In addition, after a relatively short period of wear, collections of lint appear on the surface giving the appearance of "pills" on the surface, which causes the fabric to have an unappealing, worn look ${ }^{7}$. Pilling has an accelerating effect on the rate of fibre removal from the yarn structure, and hence materially reduces the service life $^{11}$.

Cellulases have had the most impact on textile processing in recent years. The basic problem in enzyme biosynthesis by microorganisms is the selection of proper producer. Among microorganisms producing cellulolytic enzymes, mesophilic filamentous fungi predominate; in this group the most interesting are strains of Trichoderma, Aspergillus, Penicillium, Fusarium, Myrothecium and Chaetomium ${ }^{12-13}$. One of the major problems encountered in the utilization of the enzymes produced by mesophilic fungi is their relatively poor temperature stability and low hydrolysis rates of lignocellulosics ${ }^{14}$. Thermophilic fungi appear to offer some major advantages for microbial technology, and a considerable amount of research on thermophiles is motivated by these potential applications ${ }^{15-16}$. However, there is paucity of information on application of thermostable cellulase in textile finishing. 
Recently, we reported that the thermophilic fungus Talaromyces emersonii could produce appreciable level of highly thermostable cellulase when grown on lignocellulosic substrate ${ }^{17}$. This work presents the results of the optimisation of conditions for cellulase biosynthesis and the evaluation of the possibilities of applying the enzyme in the pretreatment of textiles made of jute fibres.

\section{Materials and Methods}

\section{Microorganism and shake-flask cultivation}

The thermophilic fungus Talaromyces emersonii was isolated decomposing lignocellulosic materials in Bangladesh and was identified by Deutsch Sammlung von Mikaroorganisman and Zellkuluren GmbH, Germany. The fungal isolate was store in the Bangladesh Jute Research Institute, Dhaka, Bangladesh. Enzyme productions by the fungus were conducted in 300-ml Erlenmeyer flasks containing $100 \mathrm{ml}$ modified Mandels' medium ${ }^{18}$ initial $\mathrm{pH}$ 6.0 , unless otherwise mentioned. The inoculated flasks were incubated in an orbital shaker incubator at $50^{\circ} \mathrm{C}$ for 7 days with an agitation rate of $180 \mathrm{rpm}$.

\section{Experimental design}

Initially, the traditional one-factor-at-a-time method was used to select the medium ingredients and their concentration for biosynthesis of cellulase by T. emersonii. In this method only a single factor varied whilst keeping the others constant. The concentrations of the selected ingredients were then optimised using two procedures, namely, Graeco Latin square design and Box-Wilson method ${ }^{19}$.

\section{Enzyme assay}

Carboxymethylcellulase (CMCase) activity was assayed as stated by Ghose ${ }^{20}$ using $1 \%$ carboxymethylcellulose-sodium salt (Sigma, USA) as substrate. CMCase assay was carried out at $50^{\circ} \mathrm{C}$ for 30 min with a reaction $\mathrm{pH} 4.8$ using $0.05 \mathrm{M}$ citrate buffers. The reducing sugars liberated were determined by the $3^{\prime}-5^{\prime}$ dinitrosalicylic acid (DNS) method ${ }^{21}$ with glucose as standard. One unit (U) of enzyme activity corresponded to $1 \mu \mathrm{mol}$ reducing sugar released per min under the standard assay conditions.

\section{Biofinishing experiments}

Fifty millilitre enzyme preparation in $0.1 M$ citrate buffer ( $\mathrm{pH} 4.5)$ was poured into a self-sealing plastic bag containing a piece (10 $\mathrm{x} 10 \mathrm{~cm}$ ) of jute-cotton blended (JC) fabric or Hessian. The fabric was soaked thoroughly and incubated at $55^{\circ} \mathrm{C}$ for 1 to $3 \mathrm{~h}$. After treatment the enzyme activity was completely inactivated by boiling in water for $5 \mathrm{~min}$. The clear reaction mixture was saved to estimate reducing sugars using the DNS method ${ }^{21}$. The enzymatically treated samples were then washed thoroughly in running tap water followed by in distilled water. The treated materials were air dried as described by Sreenath et al. ${ }^{8}$. Control samples consisted of fabrics treated in an identical manner but without enzymes. The reducing sugar levels of controls were subtracted from the experiments. Three determinations for each sample were averaged. Brightness, whiteness, softness, pilling, fuzziness and tensile strength properties were considered here for physical evaluation of the final quality of the fabrics.

\section{Biostoning experiments}

For removal of colour dye or fading of colour, cellulase enzyme from T. emersonii was applied on JC fabrics and Hessians with out pumice stone according to Kalum ${ }^{22}$. Enzymatic washing was carried out in a washing machine at $55^{\circ} \mathrm{C}$ for $30-90 \mathrm{~min}$. After enzymatic washing, the treated fabrics were boiled for $5 \mathrm{~min}$ in order to terminate the enzymatic reaction. The treated material washed thoroughly in tap water and then in distilled. Physical properties like brightness, whiteness, softness, worn out effect, tensile strength and abrasion resistance of the fabrics were then determined.

\section{Brightness and whiteness}

Brightness or whiteness index of the fabrics was measured on a photovolt reflection meter (Model 46225). Photovolt Indianapolis Mitsubishi Yasci Co., USA) using green filter of known reflectance value (93\%) with reference to magnesium oxide as $100 \%$ brightness value. After setting the voltmeter according to manual, 20 readings were taken randomly. The averages were considered as appropriate brightness and whiteness.

\section{Test for softness, pilling and fuzziness}

The softness was determined by "touching and feeling" method. The samples (control and enzyme-treated) were tested by an expert who has experience to evaluate the softness of the samples. The expert graded the samples in three categories: soft, moderate soft and hard. Pilling and fuzziness of fabrics were determined by visual inspection by an expert.

\section{Tensile strength}

Determination of tensile strength was made on fabric materials conditioned in the open piece for not less than $24 \mathrm{~h}$ in an atmosphere having a relatively humidity of $65 \pm 2 \%$ and a temperature of $20 \pm 2^{\circ} \mathrm{C}$. The test was carried out under the same conditions of temperature and relative humidity. Fabric specimens ( $30 \mathrm{~cm}$ long and $5 \mathrm{~cm}$ wide) were cut from the sample, five in each direction wrap and weft. The determination of tensile strength of fabrics was carried out according to British standard ${ }^{23}$ on a horizontal testing machine (Instron, Norwood, USA; Model 5565) with a cross head speed of $300 \mathrm{~mm} / \mathrm{min}$ and a gauge length of 50 $\mathrm{cm}$. Determination were made on each set of five specimens and the average for each set taken.

\section{Abrasion resistance}

Abrasion resistance was tested for jute fabrics according to American Standard of Textile methods ${ }^{24}$ using rotary platform abrasion resistance tester (Testrite Ltd., Woodfield Works, UK, Model WT 37). A conditioned specimen was abraded using rotary rubbing action under controlled conditions of pressure and abrasive action. The test specimen mounted on a platform, turns of a vertical axis against the sliding rotation of two abrading wheels. 
One abrading wheel rubs the specimen outward toward the periphery and the other inward toward the centre. The resulting abrasion marks form a pattern of crossed arcs over an area of approximately $30 \mathrm{~cm}^{2}$. Resistant to abrasion was evaluated as number of rotation.

\section{Results and Discussion}

It was observed from the previous study ${ }^{17}$ that the thermophilic fungus T. emersonii could produce highly thermostable cellulase. In this study the optimisation experiments were carried out to improve the cellulase production by the fungus. Special emphasis was given on the development of a simple and cheap culture medium for the enzyme production. Table 1 summarizes the effect of culture conditions on production of cellulase (CMCase) by the thermophilic fungus T. emersonii in shake-flask cultures using sugar cane bagasse as substrate. The fungus produced the highest amount of cellulase in the medium with initial $\mathrm{pH} 6.0$ at $50^{\circ} \mathrm{C}$. The specific growth rate of the fungus was, however, higher when the initial $\mathrm{pH}$ was 5.5 and the incubation temperature was $45^{\circ} \mathrm{C}$. The enzyme activity reached to maximum at 7 days of incubation, which corresponded to $2.06 \mathrm{U} / \mathrm{ml}$ cellulase activity. The agitation speed in shake-flask cultures greatly influenced the enzyme production. A shifting of agitation speed from 120 rpm to 180 rpm caused 2-fold increase in the enzyme activity.

Table 1. Effect of culture conditions for production of cellulase from Talaromyces emersonii in shake-flask cultivations

\begin{tabular}{|c|c|c|}
\hline $\begin{array}{l}\text { Culture } \\
\text { condition }\end{array}$ & $\begin{array}{c}\text { CMCase activity } \\
(\mathrm{U} / \mathrm{ml})\end{array}$ & $\begin{array}{c}\text { Relative activity } \\
(\%)\end{array}$ \\
\hline \multicolumn{3}{|l|}{ Initial $\mathrm{pH}$} \\
\hline 5.0 & 1.52 & 76 \\
\hline 5.5 & 1.88 & 94 \\
\hline 6.0 & 2.00 & 100 \\
\hline 6.5 & 1.82 & 91 \\
\hline 7.0 & 1.24 & 62 \\
\hline 7.5 & 1.00 & 50 \\
\hline \multicolumn{3}{|c|}{ Incubation temperature $\left({ }^{\circ} \mathrm{C}\right)$} \\
\hline 40 & 1.40 & 62 \\
\hline 45 & 2.20 & 98 \\
\hline 50 & 2.25 & 100 \\
\hline 55 & 2.05 & 91 \\
\hline 60 & 1.60 & 71 \\
\hline \multicolumn{3}{|c|}{ Incubation period (Days) } \\
\hline 5 & 1.80 & 88 \\
\hline 6 & 1.92 & 94 \\
\hline 7 & 2.06 & 100 \\
\hline 8 & 2.01 & 98 \\
\hline 9 & 1.82 & 89 \\
\hline \multicolumn{3}{|c|}{ Agitation speed (rpm) } \\
\hline 120 & 1.18 & 50 \\
\hline 150 & 1.66 & 70 \\
\hline 180 & 2.37 & 100 \\
\hline
\end{tabular}

Since the production of microbial enzymes has a large impact on the overall microbial process economy ${ }^{25}$, the present study aimed to choose inexpensive and readily available effective substrate in cellulase production by the fungus. Initially, the traditional one-fact-at-a-time method was employed for selection of appropriate medium ingredients and their apparent concentrations of the enzyme production. It was found that sugar cane bagasse as carbon source, peptone as organic and $\mathrm{NH}_{4} \mathrm{HPO}_{4}$ as inorganic nitrogen sources, and $\mathrm{KH}_{2} \mathrm{PO}_{4}$ as buffering agent as well as source of ions to be considered as the major ingredients for cellulase biosynthesis by the fungus. The concentrations of these factors were optimised by using two statistical methods, namely, Graeco Latin square and Box-Wilson methods ${ }^{19}$. Table 2 summarizes the experimental design of Graeco Latin square method and the corresponding enzyme activities. It was found that a medium containing $2.0 \%$ sugar cane bagasse, $1.0 \%$ peptone, $0.7 \%$ $\mathrm{NH}_{4} \mathrm{HPO}_{4}$ and $0.5 \% \mathrm{KH}_{2} \mathrm{PO}_{4}$ supported good growth and the enzyme production by the fungus. By summing up the cellulase activities obtained with here respective media for a single concentration of the selected ingredient, it was apparent that the best concentrations of sugar cane bagasse, peptone, $\mathrm{NH}_{4} \mathrm{HPO}_{4}$ and $\mathrm{KH}_{2} \mathrm{PO}_{4}$ were 2.0, 1.0, 0.7 and $1.0 \%$ respectively. It was also realized that $\mathrm{NH}_{4} \mathrm{HPO}_{4}$ concentrations (0.2-0.5\%) used had little effect on the enzyme production. Therefore, $\mathrm{NH}_{4} \mathrm{HPO}_{4}$ concentration was not further optimised, while the concentrations of the other ingredients were more accurately determined by using a $2^{3}$ factorial experiment, known as Box-Wilson method ${ }^{19}$.

Table 2. Design for optimisation of ingredient concentrations of culture medium for cellulase production by Talaromyces emersonii using Graeco Latin square technique and the corresponding enzyme activities

\begin{tabular}{lccccc}
\hline $\begin{array}{l}\text { Medium } \\
\text { No. }\end{array}$ & \multicolumn{4}{c}{ Medium ingredient } & \begin{tabular}{c} 
Cellulase \\
activity \\
\cline { 2 - 5 }
\end{tabular} \\
\cline { 2 - 5 } & Bagasse & Peptone & $\mathrm{NH}_{4} \mathrm{HPO}_{4}$ & $\mathrm{KH}_{2} \mathrm{PO}_{4}$ & \\
\hline 1 & 1.5 & 0.5 & 0.2 & 0.5 & 1.91 \\
2 & 2.0 & 0.5 & 0.5 & 1.5 & 2.85 \\
3 & 2.5 & 0.5 & 0.7 & 1.0 & 1.87 \\
4 & 1.5 & 1.0 & 0.5 & 1.0 & 2.23 \\
5 & 2.0 & 1.0 & 0.7 & 0.5 & 3.21 \\
6 & 2.5 & 1.0 & 0.2 & 1.5 & 2.05 \\
7 & 1.5 & 1.5 & 0.7 & 1.5 & 2.07 \\
8 & 2.0 & 1.5 & 0.2 & 1.0 & 3.06 \\
9 & 2.5 & 1.5 & 0.5 & 0.5 & 2.01 \\
\hline
\end{tabular}

In addition, each medium at an initial $\mathrm{pH} 6.0$ contained $0.3 \% \mathrm{MgSO}_{4}$. $7 \mathrm{H}_{2} \mathrm{O}$.

In the first step, two levels of each factor were run in combination with all others. The levels chosen were varied in same amount above and below the base levels ( $2.0 \pm 0.2 \%$ sugar cane bagasse, $1.0 \pm 0.2 \%$ peptone and $1.0 \pm 0.2 \% \mathrm{KH}_{2} \mathrm{PO}_{4}$ ). The design and the results of this experiment are shown in Table 3. From these data the regression coefficient values were determined for the calculation of new variables for the second experiment to obtain 
the steepest ascent or maximum response. In this experiment, the level of sugar cane bagasse was decreased arbitrarily and serially by $0.05 \%$, and proportionately and serially the level of peptone was decreased by $0.08 \%$ and the level of $\mathrm{NH}_{4} \mathrm{HPO}_{4}$ decreased by $0.04 \%$. The design of the second experiment to obtain the ascent and the corresponding enzyme activities are summarized in Table 4 . The yield plateau with respect to cellulase activity was reached at maximum in the medium (Medium 3 ) containing 1.90\% sugar cane bagasse, $0.84 \%$ peptone and $0.92 \% \mathrm{KH}_{2} \mathrm{PO}_{4}$, in addition to $\mathrm{NH}_{4} \mathrm{HPO}_{4} 0.7 \%$ and $0.3 \% \mathrm{MgSO}_{4}$. The optimized medium gave $3.90 \mathrm{U} / \mathrm{ml}$ cellulase activity. Mathematical methods of optimisation using multidimensional plans provide quick and effective development of the optimum values ${ }^{13}$. The medium thus developed might be economically feasible for large-scale production of cellulase by $T$. emersonii.

Table 3. First experimental design of Box-Wilson method for optimisation of ingredient concentrations of culture medium for cellulase production by Talaromyces emersonii and the corresponding enzyme activities

\begin{tabular}{lcccc}
\hline Medium & \multicolumn{3}{c}{ Medium ingredient } & $\begin{array}{c}\text { Cellulase } \\
\text { No.tivity } \\
\end{array}$ \\
\cline { 2 - 4 } & Bagasse & Peptone & $\mathrm{KH}_{2} \mathrm{PO}_{4}$ & $(\mathrm{U} / \mathrm{ml})$ \\
\hline 1 & $1.8[-1]$ & $0.8[-1]$ & $0.8[-1]$ & 3.55 \\
2 & $1.8[-1]$ & $0.8[-1]$ & $1.2[+1]$ & 3.76 \\
3 & $1.8[-1]$ & $1.2[+1]$ & $0.8[-1]$ & 3.25 \\
4 & $1.8[-1]$ & $1.2[+1]$ & $1.2[+1]$ & 3.17 \\
5 & $2.2[+1]$ & $0.8[-1]$ & $0.8[-1]$ & 3.43 \\
6 & $2.2[+1]$ & $0.8[-1]$ & $1.2[+1]$ & 3.20 \\
7 & $2.2[+1]$ & $1.2[+1]$ & $0.8[-1]$ & 3.40 \\
8 & $2.2[+1]$ & $1.2[+1]$ & $1.2[+1]$ & 3.06 \\
Base level & 2.0 & 1.0 & 1.0 & \\
Coding unit & 0.2 & 0.2 & 0.2 & \\
Regression & & & & \\
co-efficient & & & & \\
(slope $b$ ) & -0.59 & -1.01 & -0.49 & \\
Coding unit & & & & \\
x slope $b$ & -0.118 & -0.202 & -0.98 & \\
\hline
\end{tabular}

In addition, each medium at an initial $\mathrm{pH} 6.0$ contained $0.7 \% \mathrm{NH}_{4} \mathrm{PO}_{4}$ and $0.3 \% \mathrm{MgSO}_{4} .7 \mathrm{H}_{2} \mathrm{O}$.

Cellulase enzymes have found vast application in finishing cotton, jute and other natural fibres with the goal of improved hand and appearance ${ }^{2-4,5,7}$. Enzymatic hydrolysis is a very complex, not yet fully understood process involving mechanisms of synergism and inhibition of the different enzyme components and their hydrolysis products. The culture of T. emersonii might contain the major groups of hydrolases required for degradation of polymers of plant cell wall materials. The effect of enzymatic treatment on release of total reducing sugar from jute-based fabrics was studied and the results are shown in Table 5. The reducing sugar released was related to enzyme concentration and treatment period. High enzyme concentration gave high saccharification value, and the accumulation of reducing sugar reached to maximum after $2 \mathrm{~h}$ reaction time. Therefore, the further pretreatment experiments on jute-based fabrics were carried out using high concentration (enzyme to buffer ratio 1:1) of the enzyme preparation with a treatment period of $2 \mathrm{~h}$.

Table 4. Second experimental design of Box-Wilson method for optimisation of ingredient concentrations of culture medium for cellulase production by Talaromyces emersonii and the corresponding enzyme activities

\begin{tabular}{lcccc}
\hline \multirow{2}{*}{$\begin{array}{l}\text { Nodium } \\
n\end{array}$} & \multicolumn{3}{c}{ Medium ingredient } & \begin{tabular}{c} 
Cellulase \\
activity \\
\cline { 2 - 4 }
\end{tabular} \\
\cline { 2 - 4 } Bagasse & Peptone & $\mathrm{KH}_{2} \mathrm{PO}_{4}$ & $(\mathrm{U} / \mathrm{ml})$ \\
\hline 2.00 & 1.00 & 1.00 & 3.58 \\
3 & 1.95 & 0.92 & 0.96 & 3.69 \\
4 & 1.90 & 0.84 & 0.92 & 3.90 \\
5 & 1.85 & 0.76 & 0.88 & 3.52 \\
6 & 1.80 & 0.68 & 0.84 & 3.43 \\
7 & 1.75 & 0.60 & 0.80 & 3.20 \\
8 & 1.70 & 0.52 & 0.76 & 3.04 \\
\hline
\end{tabular}

Decreased bagasse level serially and arbitrarily by $0.05 \%$, decreased peptone level serially and proportionally by $0.08 \%(0.202 \times 0.05 / 0.118=0.08 \%)$, and decreased $\mathrm{KH}_{2} \mathrm{PO}_{4}$ level serially and proportionally by $0.04 \%(0.098 \mathrm{x}$ $0.05 / 0.118=0.04 \%$ ). In addition, each medium at an initial $\mathrm{pH} 6.0$ contained $0.7 \% \mathrm{NH}_{4} \mathrm{PO}_{4}$ and $0.3 \% \mathrm{MgSO}_{4} \cdot 7 \mathrm{H}_{2} \mathrm{O}$.

Table 5. Effect of enzyme dilution and treatment time on Hessian and JC fabric before and after treatment

\begin{tabular}{lccc}
\hline Treatment & $\begin{array}{c}\text { Treatment } \\
\text { period } \\
\end{array}$ & $\begin{array}{c}\text { Reducing sugar released } \\
(\mathrm{mg} / \mathrm{ml})\end{array}$ \\
\cline { 3 - 4 } & 1 & JC fabric & Hessian \\
\hline Cellulase & 2 & 9.34 & 2.25 \\
$\quad$ enzyme:buffer ratio 1:1) & 3 & 10.04 & 11.48 \\
& & & \\
Cellulase & 1 & 0.97 & 0.86 \\
$\quad$ (enzyme:buffer ratio 1:2) & 2 & 4.62 & 5.10 \\
& 3 & 4.69 & 5.18 \\
Control & $1-3$ & 0.00 & 0.00 \\
\hline
\end{tabular}

Reaction condition: Temperature $=55^{\circ} \mathrm{C} ; \mathrm{pH}=5.5$; Enzyme filtrate:liquor ratio $=1: 12$; Enzyme activity $=$ Cellulase $3.55 \mathrm{U} / \mathrm{ml}$.

Table 6 shows the effect of enzymatic (cellulase) treatment on brightness and whiteness properties of jute-cotton union (JC) fabrics and Hessians. The whiteness and brightness properties of JC fabrics and Hessians were enhanced to some extended by the treatment. The brightness of JC fabrics changed from 43.73 to 46.62 and whiteness from 31.14 to 35.50 due to the treatment. The brightness of Hessians changed from 25.06 to 29.72 and whiteness from 14.58 to 17.34 after the treatment. The results indicate that the crude enzyme preparation from $T$. emersonii had bleaching properties to some extent. 
Table 6. Effect of enzymatic treatment on brightness and whiteness of JC fabric and Hessian

\begin{tabular}{lcc}
\hline Property & JC fabric & Hessian \\
\hline Brightness & 43.73 & 25.06 \\
$\quad$ Before treatment & 46.62 & 29.72 \\
After treatment & & \\
Whiteness & 31.14 & 14.58 \\
Before treatment & 35.50 & 17.34 \\
After treatment &
\end{tabular}

Values indicate the average of 20 measurements.

Biopolishing can be applied to the fabric to remove the pills and fuzz from fabric surface, to reduce the tendency of pilling, to improve the smoothness, drape, flexibility and lustre ${ }^{11}$. Biopolishing consists of a cellulase enzyme treatment to give a partial hydrolysis of cotton; so the short fibre ends are hydrolysed, leaving the surface of the fibres free and providing a more even look ${ }^{26-27}$. But it should be considered that there is also a loss of strength related to the amount of weight reduction. The effect of the T. emersonii cellulase in removing the protruding fibres was visually obvious in this study. The enzymatic treatment resulted remarkable reduction of pilling and fuzziness of the original JC fabrics and Hessians (Table 7). The treatment improved the fabric quality with respect to handle and appearance. The most important effects were less fuzz and pilling, increased gloss or lustre, improved fabric handle, and increased durable softness.

Table 7. Effect of enzymatic treatment on softness, pilling and fuzziness of JC fabric and Hessian

\begin{tabular}{lcc}
\hline Property & JC fabric & Hessian \\
\hline Softness & Hard & Hard \\
Before treatment & Very soft & Very soft \\
After treatment & Moderate & Moderate \\
Pilling & Few & Few \\
Before treatment & & \\
After treatment & Moderate & High \\
Fuzziness & Few & Moderate \\
Before treatment & & \\
After treatment & & \\
\hline
\end{tabular}

The biopolishing process partly hydrolyses the fibre, which has a negative effect on fabric strength level ${ }^{11}$. In this study, the tensile strength retention was more than $90 \%$ for all enzyme treatment up to $2 \mathrm{~h}$ reaction time (Table 8). The warp and weft values were respectively 7.7 and $6.3 \%$ decreased due to enzymatic treatment of JC fabrics, and 6.5 and $5.4 \%$ decreased due to enzymatic treatment of Hessians. The fabric samples' strength loss caused by enzymatic treatment is nearly the same in all type of fabrics, approximately around $11 \%{ }^{11}$. Therefore, it should be cautioned that over enzymatic treatment might cause severe strength loss beyond acceptable limits. This may be explained by the mechanism of biopolishing. Enzymes are surface-active; during biopolishing process, they will most probably act mainly on the protruding excessive fibrilious surfaces, and also on the outer surfaces of the yarn. If we employ a second biopolishing process, enzymes will react on the increased surface area, and they will damage the yarn sufficiently to cause severe strength and weight loss. Although twice bio-polishing improves pilling properties, this will take place at the expense of basic fabric requirements such as strength and weight ${ }^{11}$.
Table 8. Effect of enzymatic treatment on average tensile strength of JC fabric and Hessian

\begin{tabular}{lcc}
\hline Treatment & \multicolumn{2}{c}{ Tensile strength } \\
\cline { 2 - 3 } & JC fabric & Hessian \\
\hline Before treatment & 131 & 188 \\
$\quad$ Warp & 159 & 143 \\
$\quad$ Weft & & \\
After treatment & 124 & 176 \\
$\quad$ Warp & 149 & 132 \\
$\quad$ Weft & & \\
Percentage reduction & 7.7 & 6.5 \\
$\quad$ Warp & 6.3 & 5.4 \\
$\quad$ Weft & & \\
\hline
\end{tabular}

Biofinishing of cotton with cellulases is well established for obtaining "stonewashed" effects on denims and for imparting softness, smoothness, and low pilling benefits to cotton fabrics ${ }^{28-29}$. Conventional stone washing uses abrasive pumice stones in a tumbling machine to abrade and remove particles of indigo dyestuff from the surfaces of denim yarns and fabric ${ }^{28,30}$. Cellulase enzymes can also cut through cotton fibres and achieve much the same effect without the damaging abrasion of the stones on both garment and machine, eliminates the disposal of the used stones, improves the quality of the waste water and eliminates the need for labour intensive removal of stones from the finished garments ${ }^{29}$.

In the present study, the enzyme of T. emersonii exhibited good biostoning or biowashing effect on JC fabrics and Hessians. The original coloured materials were faded due to the treatment with using biowashing steps. Figure 1 shows the effect of the enzymatic treatment on coloured Hessians. It was apparent that the enzyme works in the process by loosen the indigo dye on the fabrics. The physical properties changes due to biowashing are summarized in Table 9 . The whiteness and brightness of JC fabrics and Hessians were increased to some extent. Biostoning showed little detrimental effect on the tensile strength of the jute-based fabrics; the warp weft values of the fabrics reduced to less than $10 \%$ due to the enzymatic treatment. The enzymatic treatment also slightly accelerated the abrasion. However, the treatment did not achieve much worn out look of the treated fabrics. Therefore, highly abraded finishes would not be achieved just by using the cellulase alone. A partial substitution of stones with the enzymes might achieve the desired look.

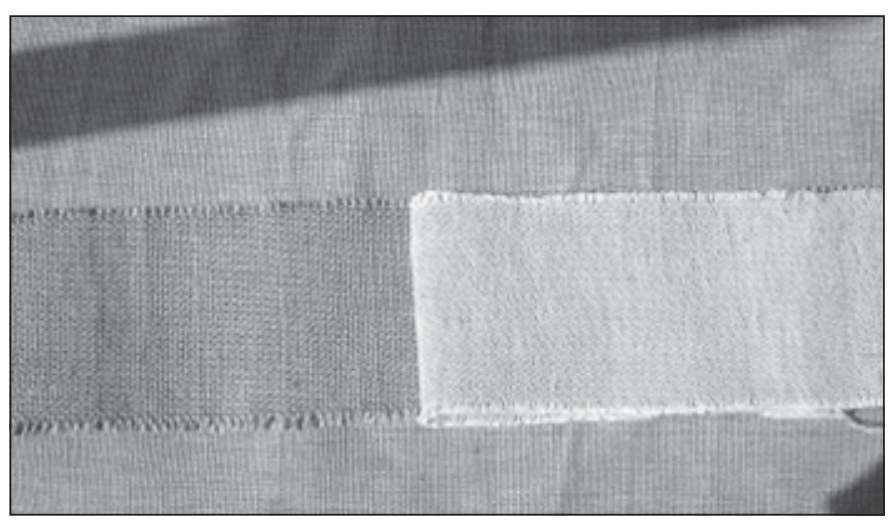

Figure 1. The appearance of Hessian before (left) and after (right) enzymatic treatment with culture filtrate of Talaromyces emersonii 
Table 9. Effect of biostoning physical properties of JC fabric and Hessian

\begin{tabular}{|c|c|c|c|c|c|c|}
\hline \multirow[t]{2}{*}{ Property } & \multicolumn{3}{|c|}{ JC fabric } & \multicolumn{3}{|c|}{ Hessian } \\
\hline & $\begin{array}{c}\text { Before } \\
\text { treatment }\end{array}$ & $\begin{array}{c}\text { After } \\
\text { treatment }\end{array}$ & $\begin{array}{c}\text { Change } \\
(\%)\end{array}$ & $\begin{array}{c}\text { Before } \\
\text { treatment }\end{array}$ & $\begin{array}{c}\text { After } \\
\text { treatment }\end{array}$ & $\begin{array}{c}\text { Change } \\
(\%)\end{array}$ \\
\hline Brightness & 43.7 & 45.4 & $\uparrow 3.7$ & 25.1 & 28.5 & $\uparrow 13.5$ \\
\hline Whiteness & 31.1 & 34.9 & $\uparrow 12.2$ & 14.6 & 16.8 & $\uparrow 15.1$ \\
\hline Tensile strength (Warp/Weft) & $131 / 159$ & $121 / 145$ & $\downarrow 7.6 / 8.8$ & 188/143 & $174 / 129$ & $\downarrow 7.5 / 9.8$ \\
\hline
\end{tabular}

The thermophilic fungus T. emersonii could be considered as a potential source of cellulase for textile finishing processes. The results of the statistical optimisation indicated the fungus could produce appreciable amount of cellulase under submerged cultivation using simple and cheap culture medium. The cellulase enzyme showed good biofinishing and biostoning effect on jutebased fabrics. It is expected that the polishing or finishing action would be further improved by optimisation of treatment procedures.

\section{Acknowledgement}

This study was financed in part by the University Grant Commission of Bangladesh.

\section{References}

1. Drury K \& Slater K. 1995. Fibres and the environment. Can Textile J. 112: $13-15$.

2. Buschle-Diller G, Zeronian SH, Pan N \& Yoon M-Y. 1994. Enzymatic hydrolysis of cotton, linen, ramie, and viscose rayon fabrics. Textile Res J. 64: 270-279.

3. Pedersen GL, Screws GA \& Cedroni DM. 1992. Biopolishing of cellulosic fabrics. Can Textile J. 109: 31-35.

4. Buschle-Diller G, Walsh WK, Ida E, Reed IE \& Radhakrishnaiah P. 1997. Effect of enzymatic treatment on dyeing and finishing of cellulosic fibres: A study of the basic mechanisms and optimisation of the process. National Textile Centre Research Brief. Available at: www.p2pays.org/ref/08/07025.pdf. Accessed 26 February 2005.

5. Tyndall RM. 1992. Application of cellulase enzymes to cotton fabrics and garments. Textile Chem Color. 24: 23-26.

6. Klahorst S, Kumar A \& Mullings MM. 1994. Optimising the use of cellulase enzymes. Textile Chem Color. 26: 13-18.

7. Schmidt M. 1994. Biopolishing: A new alternative finishing process for cellulose fibres. Lenzinger Ber. 74: 95-97.

8. Sreenath HK, Shah AB, Yang VW, Gharia MM \& Jeffreis TW. 1996. Enzymatic polishing of jute/cotton blended fabrics. J Ferment Bioeng. 81(1): 18-20.

9. Mohiuddin G. 1985. Enhancement of microbial growth for the improvement of spinning performance of jute cuttings. Bangladesh J Jute Fibre Res. 10: 1-6.

10. Ghose BL \& Dutta AK. 1980. Enzymatic softening and upgrading of lignocellulosic fibres. I. The softening and cleaning of low grade mesta and jute. J Textile Inst. 71: 108-116.

11. Özdil N, Özdoðan E and Öktem T. 2003. Effects of enzymatic treatment on various spun yarn fabrics. Fibres Textiles Eastern Europe. 11(4): 58-61.

12. Clarke AJ. 1997. Biodegradation of Cellulose, Enzymology and Biotechnology. Technomic Publishing Co, Inc, Lancaster, Basel.
13. Pyæ R, Sójka-Ledakowicz J \& Bratkowska H. 2003. Biosynthesis of enzymes by Aspergillus niger IBT-90 and evaluation of their application in textile technologies. Fibres Textiles Eastern Europe. 11(4): 58-61.

14. Linko M. 1977. An evaluation of enzymatic hydrolysis of cellulosic materials. Adv Biochem Eng. 5: 25-48.

15. Sonnleitner B \& Fiechter A. 1983. Advantages of using thermophiles in biotechnological processes: Expectation and reality. Trends Biotechnol. 1: 74-80.

16. Satyanarayana T, Johri BN \& Klein J. 1992. Biotechnological potential of thermophilic fungi. In Handbook of Applied Mycology (Arora DK, Elander RP \& Mukerji KG eds), Vol 4: Fungal Biotechnology, pp 729-761. Marcel Dekker Inc, New York.

17. Sarkar PK, Gomes I, Ali M \& Gomes DJ. 2006. Enzymatic desizing of jute-based fabrics with mixed enzyme system from Talaromyces emersonii. Bangladesh J Microbiol. 23(1): 8-12.

18. Mandels M \& Sternberg D. 1976. Recent advances in cellulase technology. Ferment Technol. 54: 267-286.

19. Auden J, Gruner J, Nüesch J \& Knüsel F. 1967. Some statistical method in nutrient medium optimisation. Pathol Microbiol. 30: 856-866.

20. Ghose TK. 1987. Determination of cellulases. Pure Appl Chem. 59: 257-268.

21. Miller GL. 1959. Use of dinitrosalicylic acid reagent for determination of reducing sugar. Anal Chem. 31: 426-428.

22. Kalum L. 1997. Biotechnology in Europe: Manpower, education and training. Biotechnology awareness: Skills, education and training. Novo Nordisk, Nottingham Trent University, Nottingham.

23. Anonymous. 1953. Textile and protective clothing. Determination of tensile strength. In British Standard Handbook No. 11: Methods of Test for Textiles. British Standards Institution, London. Available at: www.calpoly.edu/ it/trtl/Testing. Accessed 21 January 2005.

24. Anonymous. 2002. Standard test method for abrasion resistance of textile fabrics (ASTM D3884: rotary platform, double-head method). American Standard of Textile Methods (ASTM) International: Textile and Protective Clothing. Available at: www.calpoly.edu/ it/trtl/Testing/ abrasion.htm. Accessed January 27, 2005.

25. Eveleigh DE. 1987. Cellulase: A perspective. Phil Trans $R$ Soc Lond. 321: 435-447.

26. Nalankilli G. 1998. Application of enzymes in eco-friendly wet processing of cotton. Colourage. 45(10): 17-19.

27. Lenting HBM \& Warmoeskerken MMCG. 2001. Guidelines to come to minimized tensile strength loss upon cellulase application. J Biotechnol. 89: 227-232.

28. Almeida L \& Cavaco-Paulo A. 1993. Softening of cotton by enzymatic hydrolysis. Melliand Textilber. 74: 404-407.

29. Kochovi D, Videbaek T \& Cedroni D. 1990. Optimizing processing conditions in enzymatic stone washing. Am Dyest Rep. 79(9): 24-28.

30. Belghith H, Ellouz-Chaabouni S \& Gargouri A. 2001. Biostoning of denims by Penicillium occitanis (Pol6) cellulases. J Biotechnol. 89(2-3): 257-262. 